\title{
Thermodynamic description of alkali metal hydroxides over a wide range of temperatures, pressures and densities of aqueous fluids
}

\author{
Nikolay Akinfiev ${ }^{1, *}$ \\ ${ }^{1}$ Institute of Geology of Ore Deposits, Petrography, Mineralogy and Geochemistry RAS, \\ Staromonetnyi per. 35, Moscow 119017, Russia
}

\begin{abstract}
All available experimental data on dissociation constants of aqueous hydroxides of $\mathrm{Na}, \mathrm{K}$, and $\mathrm{Li}$ were critically assembled and together with quantum chemical estimations used to evaluate parameters of the $\mathrm{AD}$ EoS [1] for corresponding aqueous molecules $\mathrm{NaOH}_{(\mathrm{aq})}, \mathrm{KOH}_{(\mathrm{aq})}$, and $\mathrm{LiOH}_{(\mathrm{aq})}$. Use of the proposed approach allows proper prediction of the whole set of thermodynamic properties of these hydroxides over a wide range of temperatures $\left(0-800{ }^{\circ} \mathrm{C}\right)$, pressures $(0.1-800 \mathrm{MPa})$ and solvent densities $\left(0.03-1.1 \mathrm{~g} \cdot \mathrm{cm}^{-3}\right)$.
\end{abstract}

\section{Introduction}

The prediction of the dissociation constants of alkali metal hydroxides, such as $\mathrm{NaOH}$, $\mathrm{KOH}, \mathrm{LiOH}$, over a wide range of temperatures, pressures and densities of hydrothermal fluids is a principal task of modern geochemistry, since their stability influences the acidbase properties of natural fluids. The urgency of the problem is underscored by numerous experiments on the conductivity of aqueous solutions of hydroxides in the near- and supercritical regions of aqueous fluid, as well as the hydroxide distribution constants between the coexisting liquid and vapour phases of $\mathrm{H}_{2} \mathrm{O}$ ([2] and references therein). The thermodynamic description of the experiments using the Helgeson-Kirkham-Flowers (HKF) equation of state (EoS) [3], most popular in geochemistry today, is limited to fluid densities greater than $0.35 \mathrm{~g} \cdot \mathrm{cm}^{-3}$, while the use of a "density" model (see, for example, [4]) does not allow reliable extrapolation, since it contains a set of purely empirical parameters used in the interpolation procedure.

The goal of this work is to use all available experimental constants for the dissociation of alkali metal hydroxides, represented by

$$
\mathrm{MOH}_{(\mathrm{aq})}=\mathrm{M}^{+}+\mathrm{OH}^{-} \quad(\mathrm{M}=\mathrm{Na}, \mathrm{K}, \mathrm{Li}),
$$

to propose a thermodynamic description of the $\mathrm{MOH}_{(\mathrm{aq})}$ associated species valid for a wide range of temperatures $\left(0-800{ }^{\circ} \mathrm{C}\right)$, pressures $(0.1-800 \mathrm{MPa})$ and densities $(0.03-1.1$ $\left.\mathrm{g} \cdot \mathrm{cm}^{-3}\right)$ of aqueous fluid. The recently proposed EoS for the description of dissolved volatile components [1], which was subsequently successfully extended to the description

* Corresponding author: akinfiev@igem.ru 
of hydroxides of nonvolatile metalloids [5], was employed to describe the thermodynamic properties of $\mathrm{MOH}_{(\mathrm{aq})}$ associated species.

\section{Method}

The employed EoS of the dissolved component, $\mathrm{MOH}_{(\mathrm{aq})}$, is based on the known properties of the corresponding gaseous molecule, $\mathrm{MOH}_{(\mathrm{g})}$, and contains only 3 empirical parameters $(\xi, a, b)$, which characterize the free energy of hydration of $\mathrm{MOH}_{(\mathrm{g})}$ :

$$
\begin{gathered}
\mu_{a q}^{\mathrm{o}}(P, T)=\mu_{g}^{\mathrm{o}}(T)-\mathrm{R} T \ln \mathrm{N}_{\mathrm{w}}+(1-\xi) \mathrm{R} T \ln f_{1}^{\mathrm{o}}+ \\
+\mathrm{R} T \xi \ln \left(\frac{10 \mathrm{R} T}{\mathrm{M}_{\mathrm{w}}} \rho_{1}^{\mathrm{o}}\right)+\mathrm{R} T \rho_{1}^{\mathrm{o}}\left[a+b\left(\frac{10^{3}}{T}\right)^{0.5}\right],
\end{gathered}
$$

where $\mathrm{R}=8.31441 \mathrm{~J} \cdot \mathrm{mol}^{-1} \cdot \mathrm{K}^{-1}$ is the universal gas constant, $\mathrm{N}_{\mathrm{w}}=55.508 \mathrm{~mol} \cdot \mathrm{kg}^{-1}, \mathrm{M}_{\mathrm{w}}=$ $18.0152 \mathrm{~g} \cdot \mathrm{mol}^{-1}, f_{1}^{\mathrm{o}}$ is the fugacity $(\mathrm{MPa})$ and $\rho_{1}^{\mathrm{o}}$ is the density $\left(\mathrm{g} \cdot \mathrm{cm}^{-3}\right)$ of pure water at the given pressure $P$ and temperature $T(\mathrm{~K})$. The chemical potential of the considered hydroxide $\mathrm{MOH}_{(\mathrm{aq})}, \mu_{a q}^{\mathrm{o}}(P, T)$, was calculated using expression

$$
\mu_{a q}^{\mathrm{o}}(P, T)_{\mathrm{MOH}(\mathrm{aq})}=\mu_{a q}^{\mathrm{o}}(P, T)_{\mathrm{M}^{+}}+\mu_{a q}^{\mathrm{o}}(P, T)_{\mathrm{OH}^{-}}-2.303 \mathrm{R} T \log K_{d i s s}(P, T),
$$

where $K_{\text {diss }}$ stands for the experimental value of the $\mathrm{MOH}_{(\mathrm{aq})}$ dissociation constant on the molal scale, where the reaction is formulated as in eq. (1) at given temperature $T$ and pressure $P$. For reaction (1), the thermodynamic properties of the hydroxide ion, $\mathrm{OH}^{-}$, were calculated using [6], and the properties of alkali metal cations were obtained using the HKF EoS with data from the SUPCRT thermodynamic database [7]. The water properties in eq. (2) were calculated using [8].

To evaluate the thermodynamic properties of $\mathrm{MOH}_{(\mathrm{g})}$ in the ideal gas state, quantum chemical computations were employed. These were performed using the Gaussian 09W, Revision C.01 suite of programs [9] with the 6-311G+(d, p) basis set. Electron correlation effects were included by the use of density functional theory (DFT) with the hybrid functional B3LYP. A structure optimization procedure preceded the thermochemical calculations. All molecular structures were processed and analyzed for imaginary frequencies using the GaussView 5 program. The temperature dependence of the thermochemical properties was computed using a standard Gaussian procedure (the Readisotopes option).

Preliminary calculations showed that clusters of the $\mathrm{MOH}\left(\mathrm{H}_{2} \mathrm{O}\right)_{n}$ type $(n=0-6)$ may be stable in the gas phase, however $n$ decreases with rising temperature (Fig. 1). These results indicate that the $\mathrm{MOH}_{(\mathrm{g})}$ gas molecule used in the EoS (2) should be considered as a model one, while the empirical parameters of the EoS should take into account all the hydration effects of this model species, including covalently bonded water molecules.

The available experimental data on $\mathrm{MOH}_{(\mathrm{aq})}$ dissociation (Table 1) were used to evaluate $\mu_{a q, \mathrm{MOH}}^{\mathrm{o}}(P, T)$ values at the experimental $P, T$ points, and then these last were linearly regressed to determine $\mu_{g, \mathrm{MOH}}^{\mathrm{o}}(298), S_{g, \mathrm{MOH}}^{\mathrm{o}}(298), C_{p, g, \mathrm{MOH}}^{\mathrm{o}}(298)$ and the parameters $\xi$, and $b$ of the EoS (eq. 2). The retrieved values are given in Table 2. 


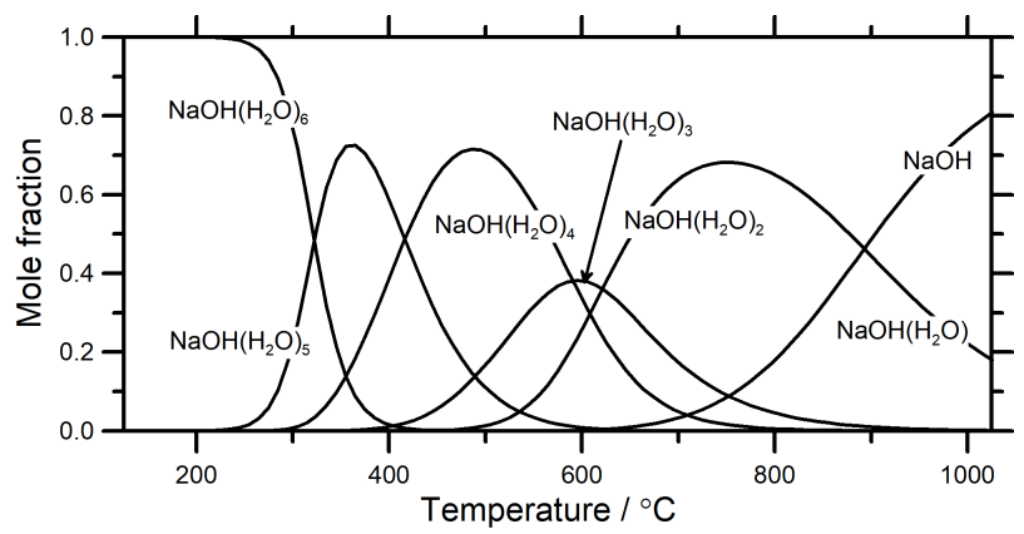

Fig. 1. Example of quantum chemical computation for $\mathrm{NaOH}\left(\mathrm{H}_{2} \mathrm{O}\right)_{n}$ speciation $(n=0-6)$ vs. temperature in gaseous phase.

Table 1. Experimental data for $\log K_{\text {diss }}$ used in the regression procedure.

\begin{tabular}{|c|c|c|c|c|}
\hline Hydroxide & $T /{ }^{\circ} \mathrm{C}$ & $P /$ bars & $\rho / \mathrm{gcm}^{-3}$ & Reference \\
\hline $\mathrm{NaOH}$ & $5-45$ & 1 & & {$[11]$} \\
\hline $\mathrm{NaOH}$ & $50-75$ & 1 & & {$[12]$} \\
\hline $\mathrm{NaOH}$ & $75-150$ & 16 & & {$[13]$} \\
\hline $\mathrm{NaOH}$ & $375-600$ & & $0.3-0.75$ & {$[14]$} \\
\hline $\mathrm{NaOH}$ & $100-405$ & $100-300$ & & {$[15]$} \\
\hline $\mathrm{NaOH}$ & $100-350$ & $70-300$ & & {$[16]$} \\
\hline $\mathrm{KOH}$ & $400-700$ & & $0.3-0.7$ & {$[17]$} \\
\hline $\mathrm{KOH}$ & 25 & 1 & & {$[18]$} \\
\hline $\mathrm{KOH}$ & $375-600$ & & $0.3-0.8$ & {$[19]$} \\
\hline $\mathrm{KOH}$ & $100-400$ & $100-300$ & $0.4-0.97$ & {$[15]$} \\
\hline $\mathrm{LiOH}$ & $15-45$ & 1 & & {$[12]$} \\
\hline $\mathrm{LiOH}$ & $400-600$ & & $0.4-0.8$ & {$[20]$} \\
\hline $\mathrm{LiOH}$ & $50-410$ & $44-350$ & & {$[15]$} \\
\hline $\mathrm{LiOH}$ & $300-370$ & & $0.1-0.7$ & {$[21]$} \\
\hline
\end{tabular}

Table 2. Thermodynamic parameters of hydroxides adopted in this study.

\begin{tabular}{|c|c|c|c|c|c|c|}
\hline Species & \multicolumn{3}{|c|}{ Ideal gas properties } & \multicolumn{3}{|c|}{ EoS parameters } \\
\hline & $\begin{array}{l}\Delta_{f} G^{\circ}{ }_{298} \\
\mathrm{~kJ} \cdot \mathrm{mol}^{-1}\end{array}$ & $\begin{array}{c}S^{\circ} 298, \\
\mathrm{~J} \cdot \mathrm{mol}^{-1} \cdot \mathrm{K}^{-1} \\
\end{array}$ & $\begin{array}{c}C_{p}(T), \\
\mathrm{J} \cdot \mathrm{mol}^{-1} \cdot \mathrm{K}^{-1}\end{array}$ & $\xi$ & $\begin{array}{c}a, \\
\mathrm{~cm}^{3} \cdot \mathrm{g}^{-1} \\
\end{array}$ & $\begin{array}{c}b, \\
\mathrm{~cm}^{3} \cdot \mathrm{K}^{0.5} \cdot \mathrm{g}^{-1}\end{array}$ \\
\hline $\mathrm{NaOH}$ & $\begin{array}{c}-317.409 \pm \\
2.6\end{array}$ & $\begin{array}{c}202.05 \pm \\
7.7\end{array}$ & $108.48 \pm 6.9$ & $\begin{array}{c}-0.260 \pm \\
0.24\end{array}$ & $\begin{array}{c}24.976 \pm \\
2.99\end{array}$ & $\begin{array}{c}-29.657 \pm \\
2.48\end{array}$ \\
\hline $\mathrm{LiOH}$ & $\begin{array}{c}-356.843 \pm \\
5.6\end{array}$ & $\begin{array}{c}216.684 \pm \\
11.9\end{array}$ & $76.50 \pm 7.4$ & $0.01 \pm 0.32$ & $\begin{array}{c}41.622 \pm \\
4.53\end{array}$ & $\begin{array}{c}-39.329 \pm \\
3.79\end{array}$ \\
\hline $\mathrm{KOH}$ & $\begin{array}{c}-344.932 \pm \\
3.6\end{array}$ & $\begin{array}{c}231.86 \pm \\
11.2\end{array}$ & $40.93 \pm 9.8$ & $\begin{array}{c}-0.544 \pm \\
0.11\end{array}$ & $\begin{array}{c}13.078 \pm \\
2.84\end{array}$ & $\begin{array}{c}-19.387 \pm \\
1.86\end{array}$ \\
\hline
\end{tabular}

\section{Results and discussion}

Use of the proposed EoS for $\mathrm{MOH}$ aqueous species $(\mathrm{M}=\mathrm{Na}, \mathrm{Li}, \mathrm{K})$ with parameters from Table 2 enables description of the whole set of available experimental data (temperatures 0 
- $600{ }^{\circ} \mathrm{C}$, pressures of $0.1-300 \mathrm{MPa}$ and solvent densities of $0.07-1.05 \mathrm{~g} \cdot \mathrm{cm}^{-3}$ ) on the dissociation constants of the hydroxides within their experimental error. It is to note that the employed EoS gives fair predictions even for the available distribution coefficient of $\mathrm{NaOH}$ between coexisting liquid and vapour phases [10], thus it is valid for water densities up to $0.03 \mathrm{~g} \cdot \mathrm{cm}^{-3}$.

Figure 2 illustrates model predictions for temperature dependences of the association constants of the hydroxides under consideration at 50 and $300 \mathrm{MPa}$.

$\mathrm{H}_{2} \mathrm{O}$ density $/ \mathrm{g} \cdot \mathrm{cm}^{-3}$

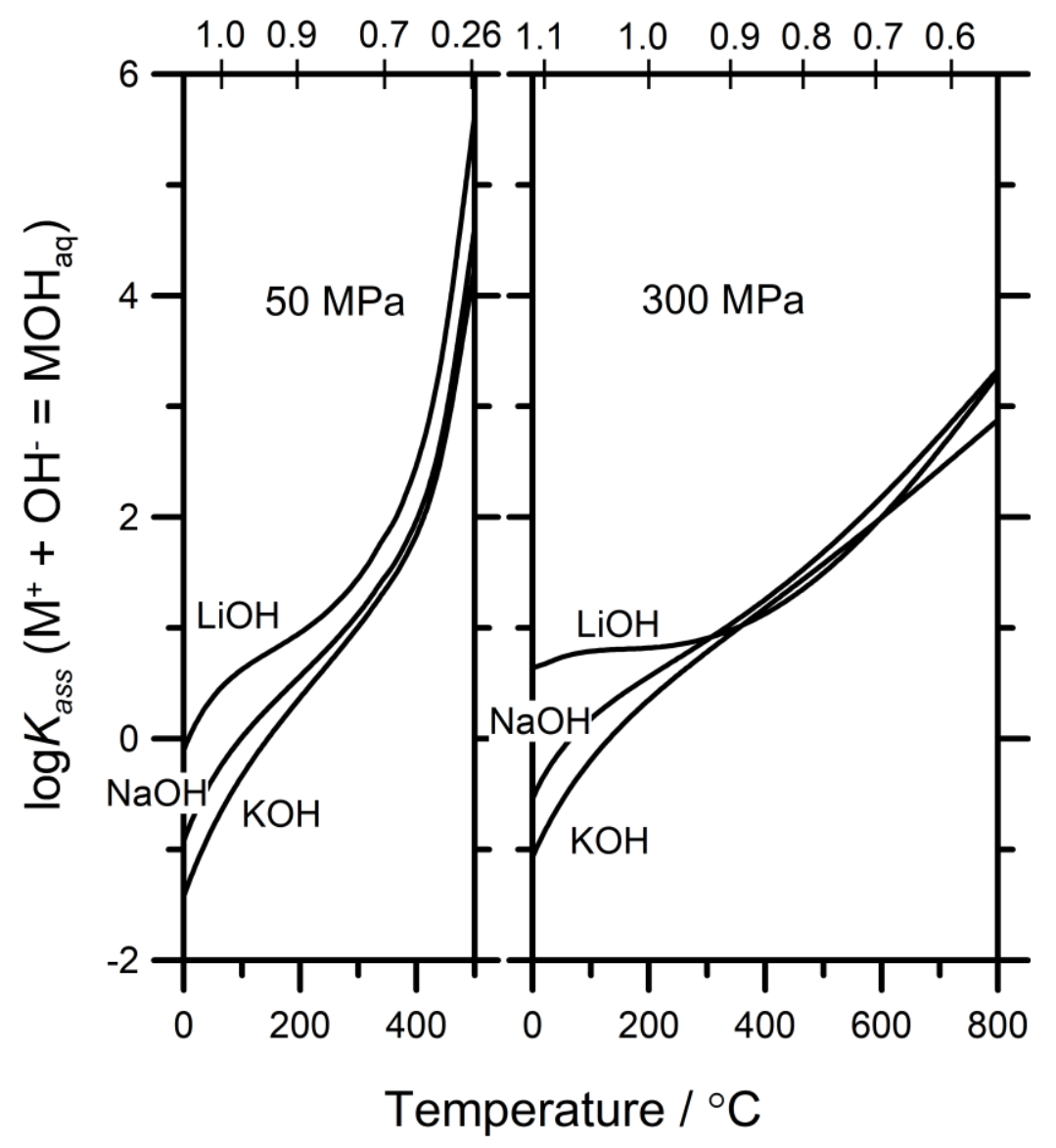

Fig. 2. Calculated temperature dependences of the decimal logarithm of association constants $\mathrm{LiOH}$, $\mathrm{NaOH}$, and $\mathrm{KOH}$ at pressures of 50 (left) and $300 \mathrm{MPa}$ (right).

It can be seen that $\mathrm{Li}$ hydroxide is the most prone to association, while $\mathrm{K}$ is the least. Increasing temperature at isobaric conditions promotes association, while the very steep rise of $\log K_{\text {ass }}$ at $T>350{ }^{\circ} \mathrm{C}$ is mainly caused by the concomitant drop in aqueous fluid density. It is also curious to note that high temperatures tend to reduce the "individuality" of the hydroxides: $\log K_{\text {ass }}$ values become close to each other at $T>400{ }^{\circ} \mathrm{C}$.

The study was supported by the Russian Academy of Sciences basic research project 0136-20180021. Author also acknowledged to L.W. Diamond for valuable corrections to the English wording. 


\section{References}

1. N.N. Akinfiev, L.W. Diamond, Geochim. Cosmochim. Acta 67, 613 (2003)

2. D.A. Palmer, R. Fernandez-Prini, A.H. Harvey (editors) Aqueous Systems at Elevated Temperatures and Pressures: Physical Chemistry in Water, Steam and Hydrothermal Solutions. Elsevier (2004)

3. J.C. Tanger, H.C. Helgeson, Amer. J. Sci., 288, 19 (1988).

4. G.M. Anderson, S. Castet, J. Schott, R.T. Mesmer, Geochim. Cosmochim. Acta, 55, 1769 (1991)

5. N.N. Akinfiev, A. V. Plyasunov, Geochim. Cosmochim. Acta, 126, 338 (2014)

6. A.V. Bandura, S.N. Lvov, J. Phys. Chem. Ref. Data, 35, 15 (2006)

7. J. W. Johnson, E. H. Oelkers, H. C. Helgeson, Comput. Geosci., 18, 899 (1992)

8. W. Wagner, A. Pruss, J. Phys. Chem. Ref. Data, 31, 387 (2002)

9. M.J. Frisch et al., Gaussian 09, Revision C.01, Gaussian, Inc., Wallingford CT (2009)

10. D.A. Palmer et al., EPRI Report TR-105801 (1999)

11. F.G.R. Gimblett, C.B. Monk, Trans. Faraday Soc., 50, 965-972 (1954)

12. H. Corti, R. Crovetto, R. Fernández-Prini, J. Solution Chem., 8, 897-908 (1979)

13. H. Bianchi, H.R. Corti, R. Fernández-Prini, Solution Chem., 23, 11, 1203-1212 (1994)

14. P.C. Ho, D.A. Palmer, J. Solution Chem., 25, 711-729 (1996)

15. P.C. Ho, D.A. Palmer, R.H. Wood, J. Phys. Chem. B, 104, 12084-12089 (2000)

16. H.R. Corti, J. M. Simonson, J Solution Chem., 35, 1057-1074 (2006)

17. E.U. Franck, Zeit Physik. Chem. Neue Folge, 8, 192-206 (1956)

18. A.J. Bard, R. Parsons, J. Jordan, Standard Potentials in Aqueous Solution (Marcel Dekker Inc., New York, 1985)

19. P.C. Ho, D.A. Palmer, Geochim. Cosmochim. Acta, 15, 3027-3040 (1997)

20. P.C. Ho, D.A. Palmer, J. Chem. Eng. Data, 43, 162-170 (1998)

21. V.N. Shcherbakov, Yu.Yu. Lukashov, Yu. M. Lukashov, Thermal Engeneering, 60, 280-284 (2013) 